\title{
Creating NACO Authority Records or Why Librarians Are Better than Google
}

By Armin Siedlecki ${ }^{1}$

Neil Gaiman, the author of Good Omens and American Gods once said in an interview, "Google can bring back 100,000 answers. A librarian can bring you back the right one." ${ }^{2}$ This quote has been understandably popular with librarians and has been cited and retweeted numerous times. The reason for this is, of course, the use of controlled vocabulary and authorized headings, which allows for targeted research with fewer ambiguities and better indexing control. While librarians are by no means the only information professionals to make use of controlled headings, they are pioneers in the field and the Name Authority COoperative Program (NACO) maintained by the Library of Congress is a good case in point.

Using the LC NACO Authority file is a common skill for catalogers and technical services librarians who know how to select the correct form of a name to use in a bibliographic record. Creating NACO authority records is perhaps less common, but it can constitute an important service for theological librarians, not only for the benefit of other Atla members, but for catalogers in general, since they are contributing information for headings in their own area of specialization and are typically more familiar with the resources that provide the relevant information. Also, the proliferation of online resources and the development of macros along with a certain relaxation of the requirements for becoming an independent NACO contributor has made the creation of authority records a less daunting task than it was even a decade ago.

When I create an authority record, I begin by searching OCLC for existing bibliographic records that may contain the same heading or perhaps different forms of the same heading. For example, I was cataloging a German book on the biblical teaching about the Holy Spirit (Die biblische Lehre vom heiligen Geist) written in 1867 by E. Quandt, Pastor der deutsch-evangelischen Gemeinde im Haag). Searching the bibliographic file for Quandt with a year span limit of 1840-1900 I came up with the following results:

- 20 entries for: Quandt, Emil, 1835-1911

- 11 entries for: Quandt, Emil (including 8 entries as QUANDT, Emil)

- 1 entry for: Quandt, Em.

- 1 entry for: Quandt, E., 1835-1911

All 33 hits were German publications and dealt with biblical or theological topics. There were other Quandts, but none whose first name began with E, so they could be safely disregarded. The most common usage was "Quandt, Emil, 1835-1911," which also provided useful dates that might be important in future disambiguations (e.g., if one day another Emil Quandt were to write one or more books).

\footnotetext{
${ }^{1}$ Armin Siedlecki is Head of Cataloging and Rare Book Cataloger at the Pitts Theology Library, Emory University.

2 https://www.youtube.com/watch?v=uH-sR1uCQ6g
} 
Next, I checked the Virtual International Authority File (VIAF; viaf.org) to see if other national libraries may have authorized entries for my author. I had already established a preferred form of the name as well as the person's birth and death dates in LC Authorities, so checking viaf.org was not necessarily required in this case, but it offered an additional source of citation and could provide further biographical details. Searching for Emil Quandt, I found an entry with the following four forms:

- Quandt, Emil, \$d 1835-1911 - used by the National Library of Lithuania, the German National Library, ISNI, and Sudoc [ABES] France

- Quandt, E. \$q (Emil), \$d 1835-1911 - used by the National Library of the Netherlands

- Quandt, Carl Wilhelm Emil \$d 1835-1911 - used by the International Inventory of Musical Sources (RISM)

- Carl Wilhelm Emil Quandt - used by Wikidata

The VIAF ID is 196190103 (Personal) and the Permalink that can be cited in subfield $\$ u$ of the 670 field is http://viaf.org/viaf/196190103. The dates were consistent with the predominant form of the name in the OCLC search and the titles associated with this ID all related to biblical or theological topics. The only additional information was a fuller form of the name Carl Wilhelm Emil Quandt, which could be used in a 400 field in an authority record to indicate an alternate form of the name.

There was one more entry with a separate VIAF ID (95654638) with the following two forms:

- Emil Quandt \$c deutscher Industrieller - used by Wikidata

- Quandt, Emil \$d 1849-1922 - used by the German National Library

The fact that the dates were different and that the person was described as a German industrialist indicated that this was a different person and that neither form would have to be considered in constructing an authority record for our theological author.

The information I had gathered was sufficient to begin constructing an authority record that would sufficiently distinguish the author from past or future authors of the same name. I completed the bibliographic record I had worked on, using the preferred form of the name in the 100 field (Quandt, Emil, \$d 1835-1911). The next step was to create the name authority record.

I could have created this record from scratch using a blank template in OCLC Connexion or apply the built-in Connexion macro "Generate Authority Record." This macro generates an authority record with a 100 and a 670 field and brings up a drop-down menu for entering additional information in 3xx fields, like birth and death dates, associated places and organizations, profession, field of activity, as well as gender and language. Filling in this information is relatively straight forward, but I usually use the Authority Toolkit, which was written by Gary Strawn at Northwestern University and can be downloaded for free at https:// files.library.northwestern.edu/public/oclc/. The Toolkit, which can be run like a macro directly from the bibliographic record, has greater functionality and reduces the possibility of error, since it fills in most of the information from the bibliographic record itself and supplies the correct subfields, term source codes and punctuation. Like the Connexion macro, it also allows for adding additional information from a drop-down menu, but one of its best features is the option of searching for online information and extracting relevant data from VIAF or Wikipedia (and a few other sources). Since I had already found a VIAF entry, all I needed to do was enter the VIAF ID in the search window and specify VIAF as the resource to be searched to obtain the relevant data. I was able to select and deselect information from this data and the Authority Toolkit added it in the appropriate fields and constructed two supporting 670 fields including their respective URLs. In this case, it also allowed me to add more specific birth and death dates in the 046 field.

At this point, the record contained enough information to be considered complete, but there were a few more fields I wanted to add. Associated Language (field 377) was easy, since all supporting information was in German. Profession (374), Gender (375) and Place (370) were also available on the title page of the bibliographic resource I had started with ("Pastor der deutsch-evangelischen Gemeinde im Haag"). Since Pastor in German is a male noun (the female equivalent would be Pastorin, which would have been extremely unlikely in 1867) 
I added Clergy $\$ 2$ lcsh for Profession and Males $\$ 2$ lcdgt for Gender. Haag is the German form for The Hague (Netherlands), which allowed me to populate subfields $\$ \mathrm{c}$ and $\$ \mathrm{f}$ of the 370 field. Finally, I wanted to add I wanted to add information about the author's Field of Activity (372). I decided that Preaching and Theology were two subject headings that were adequately descriptive and would avoid confusion with the German Industrialist, who had the same name as our author, albeit different birth and death dates. Working with the Authority Toolkit, I ended up with the following record, which I could then save to either my local or online Authority save file in Connexion and make it available for review or produce and post it directly to the NACO Authority file.

- 046:_: \$f 1835-02-10 \$g 1911-01-26 \$2 edtf

- 100:1_: \$a Quandt, Emil, \$d 1835-1911

- 372:__: \$a Preaching \$a Theology $\$ 2$ lcsh

- 374:__: \$a Clergy $\$ 2$ lcsh

- 375:__: \$a Males $\$ 2$ lcdgt

- 400:1_: \$a Quandt, E. \$q (Emil), \$d 1835-1911

- 400:1_: \$a Quandt, Carl Wilhelm Emil \$d 1835-1911

- 670:__: \$a Die biblische Lehre vom heiligen Geist, 1867: \$b title page (E. Quandt)

- 670:_: \$a Wikidata via VIAF, Sept. 3, 2019 \$b (born: 1835-02-10; died: 1911-01-26; preferred: Carl Wilhelm Emil Quandt; variant: Carl Wilhelm Emil Quandt; Carl Wilhelm Emil Quandt evangelischer Pfarrer und Superintendent; Carl Wilhelm Emil Quandt hymne-schrijver uit Duitse Keizerrijk (1835-1911); country: None; gender: 1) \$u http://www.viaf.org/processed/ WKP\%7CQ1041075

- 670:_- \$a National Library of Lithuania via VIAF, Sept. 3, 2019 \$b (preferred: Quandt, Emil 18351911; country: Germany; gender: Males; lang. code: deu; variant: Quandt, E.; Quandt, Carl Wilhelm Emil; biographical/historical: 1835-1911) \$u http://www.viaf.org/processed/ LIH\%7CLNB:C28_p_;=BT

The toolkit had generated 400 fields (alternate access points), based on the information contained in the bibliographic record I had used and the data extracted from VIAF. It had also either supplied or prompted for the correct term source codes in the various subfields $\$ 2$, information which I had always found easy to overlook or mistype if had to enter it manually.

There are of course cases that require more initial research. In this situation, there were a number of bibliographic records in OCLC with established usages and several controlled forms of the name could be found in VIAF. More detective work may be required if the author had only one or two little known publications, or if the author's used name is only available in abbreviated form. To obtain fuller information, online or print biographical resources may have to be consulted. In such instances, Google may be a good starting point, which brings us full circle. Google may return 100,000 answers, but it is the sorting and organizing of these answers and the creation of controlled headings by catalogers that will help determine the right one. 